\title{
Exploring the global media image of solar power
}

\author{
Kalle Nuortimo, University of Oulu \\ Information and Communication Studies, \\ Industrial Engineering and Management \\ University of Oulu, Finland \\ P.O. Box 4610, FI-90014, Finland \\ e-mail:kalle.nuortimo@amecfw.com \\ Janne Härkönen, \\ Industrial Engineering and Management, \\ University of Oulu, Finland \\ P.O. Box 4610, FI-90014, Finland \\ e-mail: janne.harkonen@oulu.fi \\ Erkki Karvonen, University of Oulu \\ Information and Communication Studies \\ University of Oulu, Finland \\ P.O. Box 4610, FI-90014, Finland \\ e-mail:erkki.karvonen@oulu.fi
}

\begin{abstract}
This paper analyses the media image of solar power in order to understand the recent technology development trends. The increase in both solar PV panels as well as concentrated solar power plants has been influenced by decrease in solar power price, as well as subsidies and general public acceptance. This paper focuses on the latter, through quantitative media analysis.

This paper utilises a modern method for media sentiment analysis from both editorial and social media, learning machine based analysis including over 50000 data points. The results indicate that sentiment toward solar power, especially in social media, has been mostly neutral or positive thus with expected positive effect on technology market deployment.
\end{abstract}

\section{Introduction}

Due to Paris COP21 agreement being signed, the global warming, a multidisciplinary challenge for both legislators and technologists, has attracted more focus by the international media. The continuous concerns, that anthropogenic carbon dioxide $\left(\mathrm{CO}_{2}\right)$ emissions are contributing to the global climate change, and thus the need to reduce atmospheric $\mathrm{CO}_{2}$ have pushed all levels of society to solve this issue. Particularly solar power can play an important role in areas with high pollution from fossil power plants, such as in China, to meet country's energy demand and reduce greenhouse gas emissions (Wang, 2010). 
As a response to climate change, governments around the world are committed to reduce their reliance upon fossil sources of energy and to increase the use of low carbon energy sources, specifically nuclear and renewable energy (Devine-Wright, 2012). Different countries have also formulated solar energy policies to reduce dependence on fossil fuels (Solangi, et al., 2011). As a consequence, wind farms, solar panels, technologies for carbon capture and storage are now being developed at an increasing rate (Batel et al., 2013). However, CCS (Carbon Capture and Storage) does not seem to be commercialising for coal power plants (Santos, 2015). In the case of CCS, the public acceptance is seen to be crucial for the technology's successful market deployment (Huijts et al., 2012). Since 2010, the world has added more solar photovoltaic (PV) capacity than in the previous four decades and total global capacity overtook 150 gigawatts (GW) in early 2014, furthermore in the future PV's share of global electricity is estimated to reach $16 \%$ by 2050 , a significant increase from the $11 \%$ goal in the 2010 (IEA, 2014). As assessed by Turney et al., (2011), none of the environmental impacts of solar power are negative compared to traditional power generation.

\section{Literature study}

Although nuclear power and renewable power are considered as the main existing technology options for near zero emission power production, they vary from sustainability and acceptability point of view. Renewable power is considered to be sustainable, nuclear is not, and also public acceptability of nuclear power is rather low (Verbruggen. 2008). In the case of CCS, Carbon Capture and Storage from coal plants, although there is a large capacity of $\mathrm{CO}_{2}$ storage sites available globally, the public acceptance is influenced by the possibility of $\mathrm{CO}_{2}$ leaking from the storage. Furthermore, supply security would favor the CCS technology market deployment in a large scale in contrast to solar power, and also various targets to reach near zero $\mathrm{CO}_{2}$ power production in the medium term (10-20 years) in coal power production. The CCS technology communication activities have been ongoing starting from the early 2000 (Ashworth et al., 2009). It seems, that CCS technology's commercialisation is dependent on the public opinion, and also the related media communication. Recently, multiple studies have been committed on public perceptions of carbon capture and storage (CCS), and in addition there has been effort to translate such knowledge into toolkits for public engagement and communication. However at the same time, both literature and toolkits have had lesser focus to the organisational dynamics and views of project implementers with regard to public engagement (Breukers et al., 2015). It would be necessary to allow the improved understanding of the global capacity and the applicability of CCS to potentially strengthen the global trust, awareness and the public confidence in the CCS technology (de Coninck et al., 2009). Furthermore, based on a 
Granger causality test, it was found that nuclear energy can help in reducing $\mathrm{CO}_{2}$ emission, but by 2010, the renewable energy consumption had yet not reached the level of significant contribution to emission reduction (Menyah et al., 2010).

To promote the low carbon energy and associated infrastructures for tackling climate change is an essential task also for governments worldwide, however, public and, mainly, local, opposition to those infrastructures may slow down or even halt that process (Batel et al., 2013). That is why it is important to study, how the uncertainties and fears in public acceptance can boost the technology market deployment. It is to be noted, that the targets are challenging, some of which governments have now set to boost increase in the deployment of renewable energy, further giving pressure also to the systematic social science research on public engagement with renewable energy (Devine-Wright, 2012). Also, it is to be noted that without understanding the energy mix of a society, lay people may show inconsistent preferences, such as support expansion of solar power, but may not want transmission lines (Siegrist et al., 2012). However, sceptic research also exist, which does not see common future for nuclear and renewables, and depicts nuclear power as a waste of R\&D resources (Verbruggen, A. 2008).

By looking at the past, it can be observed, that some technologies have been connected with societal controversies, which have then might have led to their public rejection, emphasising the urgency to understand also the psychological features of societal acceptance of emerging technologies (Gupta et al., 2012). In addition, it has been studied, that media framing can influence to public acceptance (Heras-Saizarbitoria et al., 2011). Earlier examplecases of failed technology commercialisation exist with an indication, that the social acceptance can be a decisive factor for technologies, and that the early adoption of general public may be essential for technology acceptance (Ashworth et al., 2009). Hence, public acceptance of renewable technologies is critical factor for their successful introduction into society (Huijts, et al, 2012). Public acceptance of technologies is continuing to be a focus of scholarly attention also in case of other technologies, as can be observed from the steady rise in the number of publications and determinants investigated that are found to impact the acceptance (Gupta et al., 2012).

Recently, although there has been various studies that have investigated renewable power technology acceptance, research and development of renewable energy has been dominated mainly by technological and economic approaches to date, lacking of social science input (Devine-Wright, 2012). Most technology acceptance studies have focused on a limited set of factors that can influence public acceptance, and have not been based on comprehensive frameworks thus missing the inclusion 
of key factors in technology acceptance (Huijts, et al., 2012). The literature explaining or describing the market penetration of renewable resources is vast and growing, and mainly three types of studies have been essential, those which look at national styles of regulation, those which analyse the barriers to renewable energy, and those looking at the factors that drive local acceptance and opposition to renewable energy, often committed with surveys of public attitudes and beliefs. (Sovacool et al., 2012) The positive overall picture for renewable energy in general, and PV energy in particular, has led researchers and policy makers to believe that public acceptance is not an issue, although this acceptance, like all social processes, is not static, and it is subject to changes, thus the same occurs in the mass media coverage and framing that can affect the afore mentioned public acceptance (HerasSaizarbitoria et al., 2011). The terminology related to acceptance has recently been reviewed by Batel et al., (2013) and it can be understood to justify, legitimise and reproduce the top-down perspectives, thus focusing only on acceptance and at the same time ignore relevant issues, such as support, resistance, apathy and uncertainty. Furthermore, it is usually assumed that public attitudes would need to somewhat change in order to make the more radical scenarios of the implementation of renewable energy technologies feasible (Devine-Wright, 2007).

It has been noted how media reporting of some environmental issues is heavily influenced by sociopolitical factors over time, and has become increasingly affected by political and industry interests (Heras-Saizarbitoria et al., 2011). Sovacool et al. (2012) has described factors, such as political commitment and positive public image, which during their presence influence to the increase in market, socio-political and community acceptance of renewable electricity. Evident from the case studies by Jobert et al., (2007), the factors of social acceptance identified in the literature are visual impact, ownership, information and participation, thus acceptance related to the project implementation include local integration of the developer, the creation of a network of support, and access to ownership. In a study of Australian wind farms, four common themes were found influencing the societal acceptance, namely trust, distributional justice, procedural justice and place attachment (Hall et al., 2013).

During the growth of PV installed capacity in Spain, there has then been an intense media debate during the phase of decline experienced by the sector. This debate tended to highlight negative aspects related to the development of the PV sector. In a socio-economic environment at a time of major economic crisis on an institutional level, the predominant discourse regarding PV energy in recent years has tended to focus on the markedly conservative and non-reformist standpoint, which is, in short, in opposition to the development of renewable energies (Heras-Saizarbitoria et al., 2011). In case of local project opposition for renewable projects, there seems to be a trend to generalise the 
character of opposition movements with short-hand labels such as 'NIMBY' (Not in My Back Yard), with only minor examination of the reasons underlying that opposition (Firestone et al., 2012).

\section{Methodological approach}

The research methodology this paper applies utilises the principles of prior public acceptance studies, however, incorporating a learning machine based media-analysis consisting of utilisation of big-data of editorial and social media sources. The study is supported by a relevant literature review. The research principles have been formerly used in different fields, and public acceptance studies have been carried out with media analysis but with smaller datasets. Sentiment analysis has previously been applied for example in the field of marketing. Also, research initiatives such as creating an automatic nuclear power acceptance tools have existed (Reis et al., 2011). This study relies on a commercial software. As a new application, a similar type of method was used by Bursher et al, (2015) including media framing from editorial content and automated sentiment analysis by software. In this study, however, the application of media framing and cluster analysis was considered to be non-applicable, in addition to statistical methods. This relates mainly to comparison of editorial content with social media, and to the fact that media frame comparability between two different types of communication is challenging. Furthermore, it might also be challenging to find a suitable statistical method for data-series analysis.

Furthermore, this study combines the existing elements in a new way, thus the users of so-called social web have now a role also as a data providers, and this provides an excellent platform also for analysing public attitudes (Penalver-Martinez et al., 2014). The main reasons for choosing learning machine, big data based media-analysis method was the applicability to enormous global datasets, both from editorial content and the social media, fast data processing and also the reduces risk of bias caused by human perceptions and interpretations (Matthes \& Kohring, 2008). By adopting this type of approach, the quantity of media sources to be analysed increases significantly compared to questionnaires and interviews. Relying on a qualitative method such as research interviews would have had its drawbacks in global media coverage study, for example responses are difficult to code and answers may vary by participant and also some respondents may provide socially desirable responses, telling researchers what they think they want to hear (Sovacool et al., 2012). The analysis was conducted to clarify the social acceptance status of solar power technologies' in order to investigate the connection to recent increase in solar power technology market deployment. The analysis findings were synthesised to obtain a clear view over the effect of social acceptance on solar power technology development and market deployment. Hence, the research setting used in this 
article is media-analysis, which is approached to discover possible implications to public acceptance, political decision making and as a result, attempting to find the link also to recent increase in market deployment.

The utilised methodology can be considered as a fairly new application in the public acceptance research. After the drastic increase in number of online sources, such as discussion forums, blogs and such, the need to develop computational tools to analyse people's preferences and attitudes has become clear (Neviaroyskaya et al., 2014). Thus, opinion mining is considered to be highly active research field, which consists of natural language processing, computational linguistics and text analysis technologies with an aim to get various added-value and informational elements from users opinions (Penalver-Martinez et al., 2014).

Similar methods have previously been applied for example to financial market predictions (Nassirtoussi et al., 2014) and marketing and brand follow-ups, which are common mainly in the consumer-related manufacturing industry, where manufacturers and distributors are faced with a continuous, accumulating snow of millions of discussion forum postings (Abrahams et al., 2012). In addition, multiple systems have been constructed in order to attempt to quantify opinions from product reviews (Godpole et al., 2007). The ability to timely access customer experience feedback can be seen to represent a prerequisite for successful co-creation of processes in a service environment (Ordones et al., 2014). Therefore adopting faster, almost real time feedback from public acceptance studies can possibly facilitate decision making as well as new policy creation.

Furthermore, individuals and organisations are increasingly adopting public opinions presented in different media to their own decision making (Liu et al., 2012). Nasukawa and Yi (2003) see the local sentiment for being more reliable than a global document sentiment, thus the human evaluators often fail to agree on the global sentiment on a document (Godpole et al,. 2007). A known fact is that human analysis of text information is subject to considerable biases, such as paying more attention to opinions that are in line with their own preferences (Liu et al., 2012). Thus, it is important to identify the semantic relationships between the sentiment expressions and the subject in order to improve the accuracy of the sentiment analysis (Nasukawa et al., 2003). At the moment, research concentrated to sentiment analysis seems to move towards content, concept, and context based analysis of natural language text, in addition to application of time efficient parsing techniques suitable for big social data analysis (Cambria et al., 2013).

The main research question in this paper is, what is the current status of solar power utilisation, and its media image both in editorial and social media, and how this has affected the clean energy 
technology market deployment. The main research method is learning machine system based analysis, committed by the help of M-Adaptive software. The sources cover 3 million social media platforms, 100,000 news outlets in 71 languages in 236 regions. (M-Brain). Sentiment analysis applied in this research is based on a combination of linguistic knowledge and human aided machine learning, which means that the software makes suggestions of classifications to humans, and humans then provide feedback on correctness. Via this procedure the system learns to improve its classification of content into sentiment categories. (M-Brain). The analysis was made by inputting keyword "solar power" to M-adaptive media monitoring software. The method can be considered more quantitative analysis compared to traditional methods such as surveys. The analysis was carried out for one year time period 2.7.2015-3.7.2015, including a total of 54878 data points from both editorial publications (20 710) and SoMe -sources (34 168).

In practice, the sentiment-coding expressions in the text are first recognised and classified automatically for type, e.g. positive terms or quantifying expressions. For a given topic, and a given document matching it, the amount and type of sentiments focused on that topic are then assessed, and the overall compound judgement displayed using five options: positive, negative, neutral, mixed and unknown. According to M-Brain's internal tests, $80 \%$ of the sentiments are correct on average for a given document. It is possible that the system makes a mistake with respect to any given individual document due to inherent ambiguity in natural language. It is well-known that humans do not agree $100 \%$ in similar tests either. As is the case for any artificial system, humor, sarcasm and irony are also beyond the system's abilities to understand. The sentiment analysis, was also tested by human with random testing, agreeing with accuracy of app. 80\% indicated by software provider. However, catching the trends in the data becomes ever more accurate with the increase of the amount of documents analysed, i.e. with large volumes the overall model matches human judgement on the same data qualitatively.

\section{Results of global media-analysis of solar power}

Despite some inaccuracies in machine based analysis, the large amount of data points provides a good basis for analysing the media image/sentiment, which can be considered as an implication from public acceptance. In Figure 1, the sentiments towards solar power are visible both in editorial publications, and in the social media. 


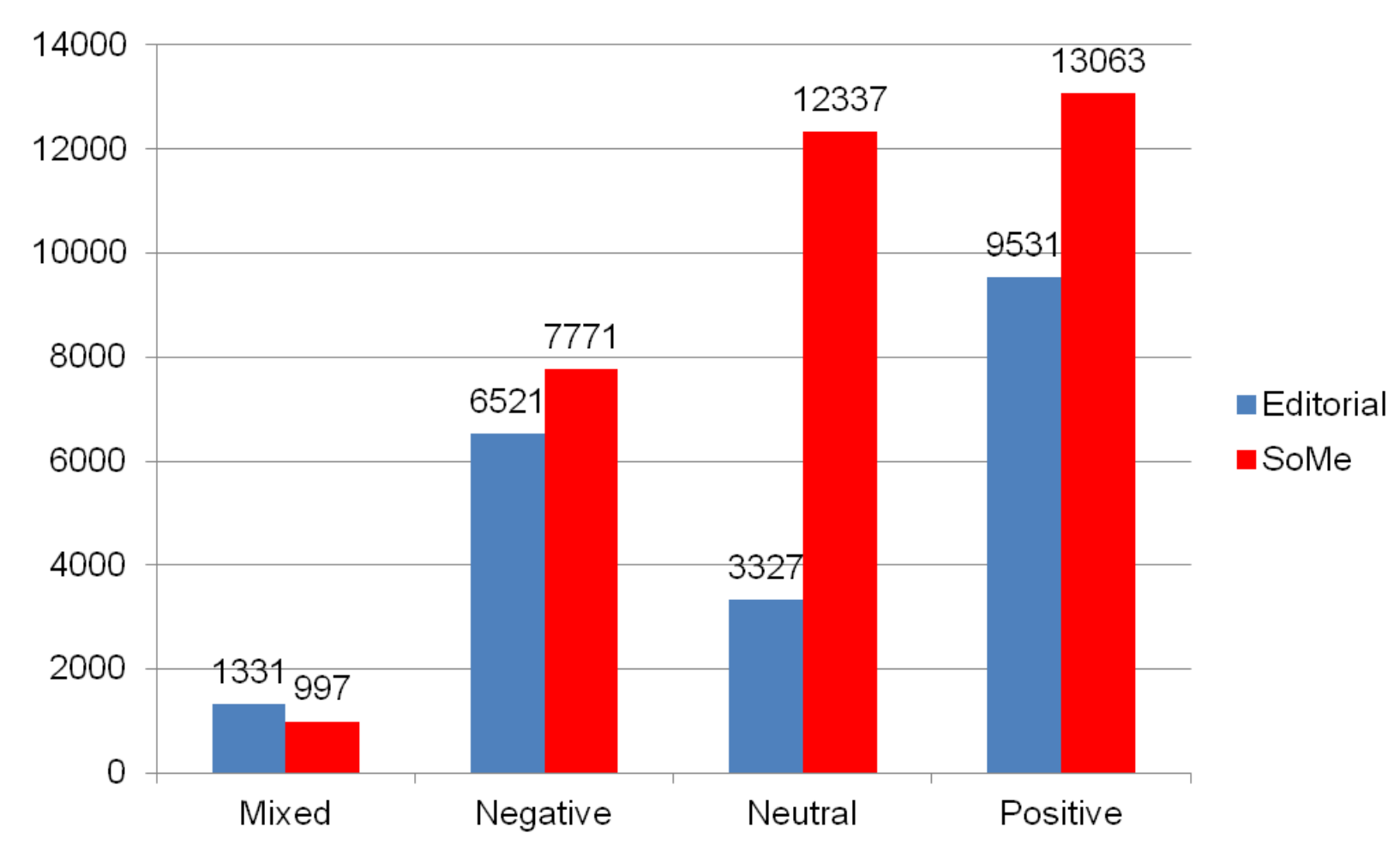

Figure 1. Sentiment analysis of Some vs. editorial publications

The results implicate that the solar power resulted mostly positive hits both in editorial publications (9531), and also in social media (13063). The amount of negative hits was 6521 in editorial content and 7771 in social media. The neutral hits were divided as a ratio of 3327 in the editorial content, and 12337 in SoMe, which indicates of more neutral views in the social media. Mixed hits, however, are concentrated to editorial content with 1331 hits compared to 997 hits in SoMe. This indicates the editorial style with inclusion of more diverse views, and also smaller effect of pure opinion.

Figure 2 illustrates how $46 \%$ of hits in editorial publications have been positive. Further analysis shows how $16 \%$ of hits in the editorial publications have been neutral indicating a relative technology acceptance among scientists, experts, and by the journalists, and also from journalistic type of discussion and rhetoric. The number of mixed (6\%) and negative (32\%) hits is relatively small, so it seems that there is an indication of a positive consensus towards solar power in editorial content. 


\section{Editorial}

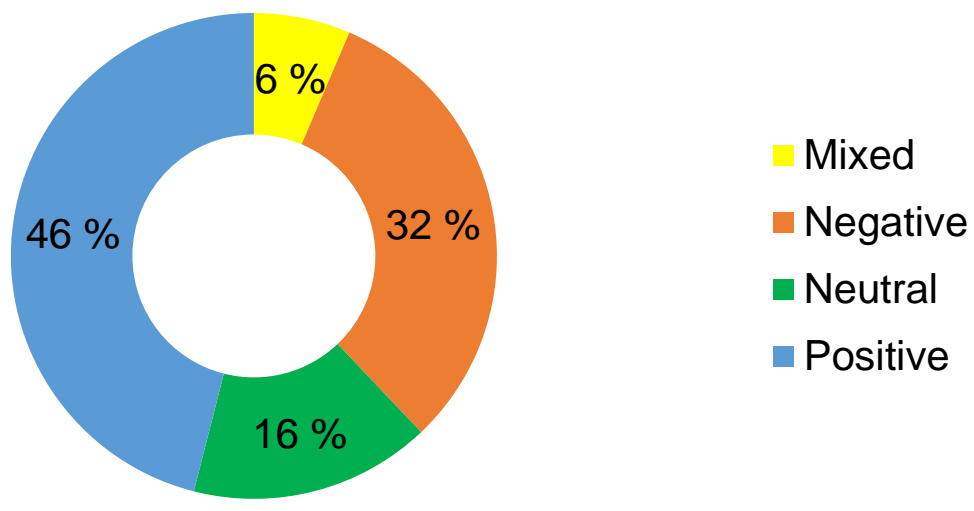

Figure 2:Sentiment analysis of Editorial publications

From the Figure 3 it is visible, that public sentiment toward solar power in social media, has been also mostly positive (38\%). Attitudes in social media appeared somewhat different compared to editorial publications. Figure 3 indicates that public sentiment toward solar power in social media is also more neutral (36\%) with a $20 \%$ difference compared to editorial publications. This can be seen as an indication that some groups have not yet decided their attitudes, which can be considered as a need to increase communication efforts in SoMe. On the other hand, the amount of positive hits was $8 \%$ smaller than in editorial publications, indicating interestingly less positive attitudes and possibly the lower levels of public acceptance than what is the "official truth" from editorial content. In mixed hits the negative difference was $3 \%$, which can possibly be seen as an indication of more strict expression views in social media. 


\section{SoMe}

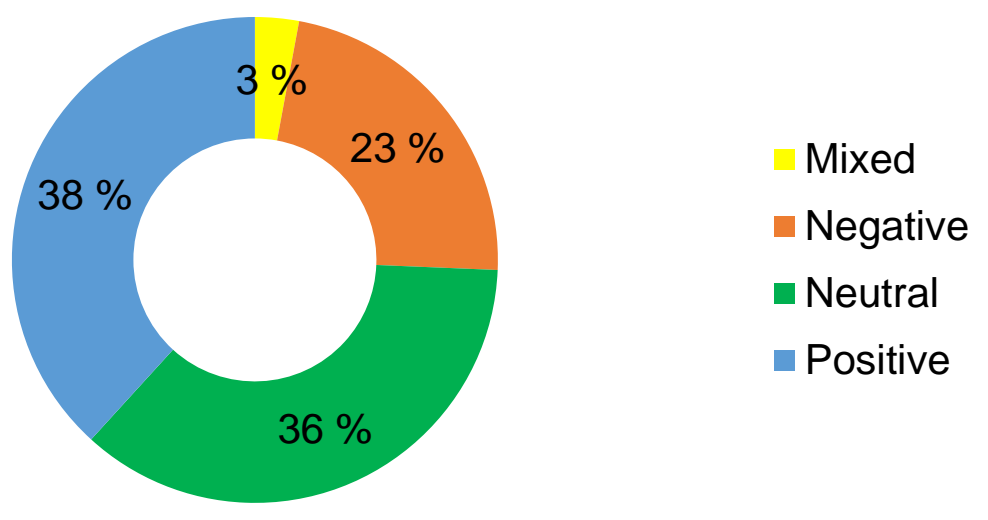

Figure 3: Solar Power's media sentiment in Social Media

From the Figure 4 it is visible how twitter has attracted most of the social media attention with over seventeen thousand hits, which have been mostly neutral (10175) or positive (4283) towards solar power, with less negative (2942) and mixed (21) hits. This can be considered as an indication of clear positive data concentration, and thus, also general neutral or positive attitudes, due negative hits are generally considered to be the most influential. Also blog writing has been active with 4431 positive hits, and 3098 negative, 672 mixed and 432 neutral. Comparing the total number of hits to Tumblr (1281), Google Plus (1697), Facebook (940) YouTube (2030), VKontakte (183), Instagram (1305) and Forums (678), short communication via Twitter (17421) can be considered as most influential of SoMe sources. Therefore, the social media can also be considered as a quite large when the public opinion towards technology is formed, although one editorial hit can have larger audience/coverage than one SoMe hit. 


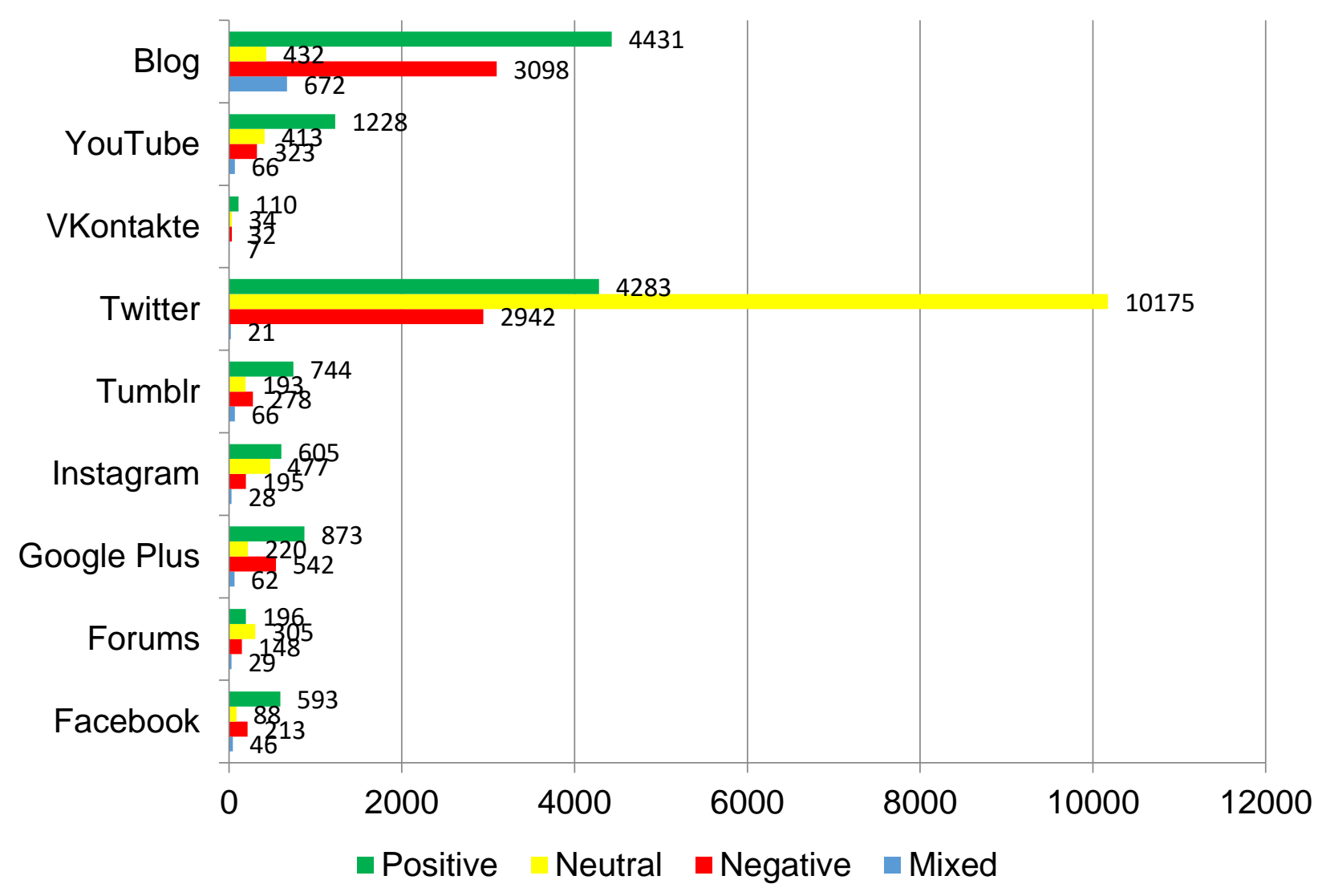

Figure 4. Deviation of social media sentiment analysis by media type

One interesting addition to the media sentiment analysis is the impact of relevant large international events (Figure 5). During the Paris COP21 negotiations between November $30^{\text {th }} 2015$ and December $11^{\text {th }} 2015$ there were a total of 8,066 hits (2947 editorial, 5119 SoMe), hence the media attention for solar power quadrupled from its regular levels compared to regular average month of hits (calculated as monthly average in 12 months' time). 


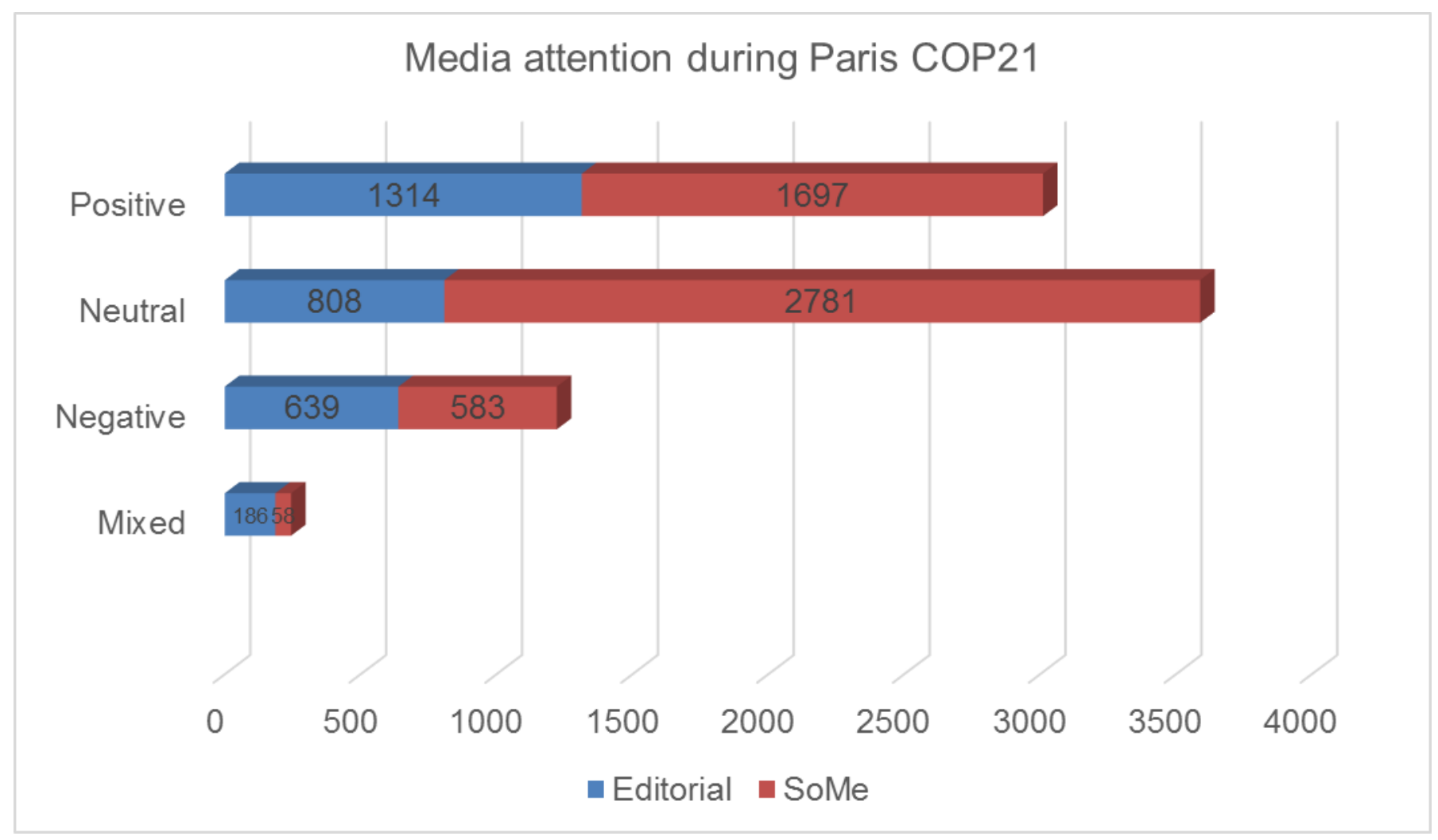

Figure 5. Solar Power Media attention during Paris COP21

From Figure 5, the effect of global Paris COP climate negotiations to solar power media image in editorial publications and SoMe was observed. The preliminary conclusion that can be drawn from entails that solar power technology seems to be considered as a solution to climate change, and thus the amount of media-attention of solar power technologies is seen to be emphasised at the time of large global climate conference. 


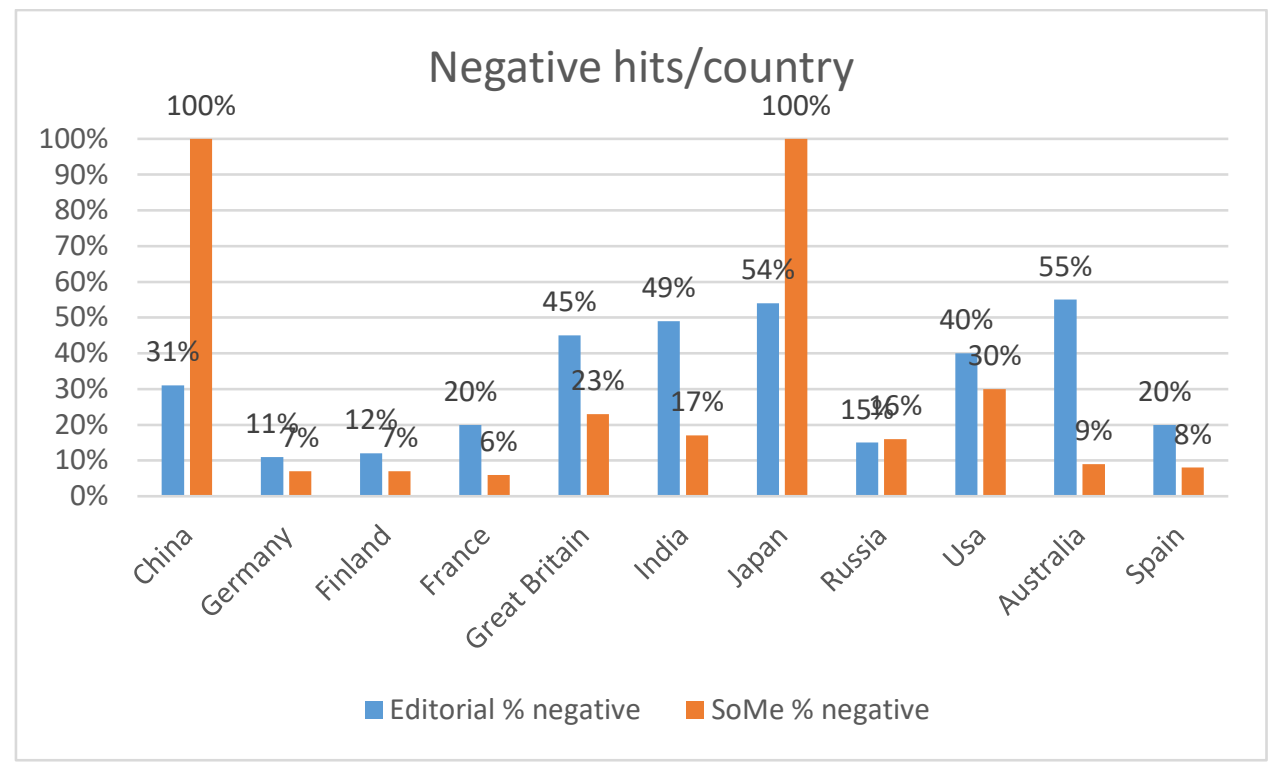

Figure 6. Negative media sentiment in selected countries

From Figure 6, it is visible, that media sentiment has also roughly followed the solar power plant newbuilding in selected countries. Germany, having large utilisation of solar power, has clearly less negative sentiments both in editorial content and in SoMe. Also Germany has renewable policies in place. Great Britain, Australia and India have clearly less negative \% in SoMe-content than editorial, indicating a more one-sided positive attitude towards solar power than in editorial content. From IEA (2016) statistics it can be compared, that solar PV increased by 27.3 TWh, mainly driven by Japan, which had increased electricity production from solar PV by 11.5 TWh, The second largest increase can be observed in the UK (3.5 TWh), followed by Italy (2.9 TWh) and Germany (2.4 TWh). The overall increase of solar power newbuilding seems to somewhat correlate with media-image in respective country, especially in the cases of Germany (lowest \% of negative hits both in editorial and in SoMe) and UK, where the less negative SoMe sentiment is in line with second largest solar power utilisation increase. In case of Japan, the hit amount in SoMe was very low, limiting the possibilities for making conclusions.

\section{Discussion}

The global media study was based on a key word based search for media hits by utilising the Madaptive software, over the time range of a one year, from July $2^{\text {nd }} 2015$ to July $3^{\text {rd }} 2016$. The total media sentiment relating to solar power was found to be generally neutral and positive in both editorial content and in SoMe. For example in Twitter, there have been active tweets concerning solar power with over thirteen thousand mostly neutral and positive hits. The analysis points out, that 
general publics' opinion can be an important factor for social acceptance and derived from that aspect, also for political decision making. Hence, from the perspective of solar power market deployment, it seems that the more positive editorial and SoMe content technology can obtain, the better. When considering the effect of relevant international events such as the global climate negotiations Paris COP 21, the media attention seems to be largely increased. In this case the effect towards solar power was mostly positive thus further strengthening the image of solar power.

The regional differences' influence on the deployment of solar power, via socio-economic factors has been described by Sovacool et al. (2012). The regional perspective has significance as although the global warming and resulting agreements are of global nature, solar power technology commercialisation itself is subject to regional politics and legislation, mainly subsidies. The further indications of of regional significance is gained by country analysis, which indicates some correlation between solar power plant newbuilding and media sentiment in each country. Good examples of this correlation include Germany with positive attitudes and also policies and newbuilding of solar power. Interesting is that solar power in arctic conditions is treated the same as solar power in equatorial area. Also, it is to be noted, that local NIMBY attitudes are not clearly visible by using the learning machine system based analysis, thus these are considered to be the smaller compared to other energy generation technologies, such as nuclear power. Nevertheless, it would seem that the main benefits of the results relate to figuring out global trends and technology development directions by using a larger data set than previous studies. This study well highlights the differences in channels of communication that affect the public acceptance, and the political decision making through citizens' opinions. The role of SoMe is continuously increasing, and presents a challenge for technology developers, but maybe also a future possibility for gaining more public acceptance. It seems that the positive link from public acceptance, favourable economics and policies to technology market deployment may exist in case of solar power.

The main contribution of this study lies in incorporating a method formerly utilised in mainly for marketing purposes to a solar power public acceptance study, therefore attempting to bring a new angle to solar power related media and social acceptance issues. Learning machine system based analysis is a new type of approach compared to several questionnaire, or interview based studies with moderate datasets of some hundred data points, that are used in most of the former similar type of studies, e.g Heras-Saizarbitoria et al., (2011). Nevertheless, the method has its positives and negatives, when compared to qualitative studies. 
Managerial implications of this paper are mainly related to, in addition to solar power investment related techno-economic and environmental considerations, also to public acceptance research method development issues. This paper utilises a new method for solar power related media analysis, a learning machine based sentiment analysis that uses a very large global dataset. This method can be applied to analyse global attitudes, and also their changes for example during the time of international events, towards technologies. Furthermore, for managers planning solar power projects, this paper highlights the needs for public engagement, and addresses the urgency for social media participation, although this is probably not so challenging issue than in the case of fossil fuels. On the contrary, compared to fossil fuel technologies, better acceptance of solar power can be considered as one advance in technology market deployment, even a key factor influencing to the issue. The overall increase of solar power newbuilding seems to correlate with media-image in respective countries, especially in the cases of Germany (lowest \% of negative hits both in editorial and in SoMe) and UK, where the less negative SoMe sentiment is in line with second largest solar power utilisation increase.

The limitations of this study include the analysed media sentiment being limited to those classifications possible with the used keywords. Hence, utilising other keywords might provide slightly different results. Also as a comparison to qualitative methods such as those used by Sovacool et al. (2013), research interviews also possess advantages, such as possible facilitation of a more complete flow of knowledge as answers are not confined to the responses and categories anticipated by the researcher, thus interviews have been one of the only ways to deal with value laden and subjective issues. This is clearly a limitation, however, compensated by global reach and fast big data analysis, giving possibility for time-trend analysis on global and also more local level in the future. In addition, no detailed content analysis was possible to commit due to large dataset, nor any framing or other discourse analysis methods were used.

As highlighted by Sovacool et al. (2013), quantitative tools and models can make it difficult to account for nuance and variance, and they also rarely look acceptance which is difficult to quantify. However, by the means of learning machine based sentiment analysis method, comparing editorial content and SoMe, certain indication of acceptance can be been seen to be gained. Therefore, it is fairly evident, that this type of approach would be well complemented by qualitative methods. Also, the ability of the software does set some limitations on the extent of possible time periods to be analysed, yet still allowing to analyse extensive data sets. The important local media sentiment has also not been analysed, such as the NIMBY syndrome (Wollsink, 2000), leaving room for future studies, yet the direct suitability of the used method for such purpose would need to be analysed. 
Agreeing with the results from Heras-Saizarbitoria et al. (2011), there seems to be a need for research that combines qualitative and quantitative approaches on the public debate and public acceptance issue of renewable energy technologies. The type of more quantitative approach used in this paper might be most useful to sight larger trends, and could be complimented in the future research by qualitative methods, which would further deepen the text analysis, such as framing and discourse analysis, also interviews. The changes that can occur in the mass media coverage and framing can affect also public acceptance (Heras-Saizarbitoria et al., 2011). This is not so visible in more quantitative approach.

\section{Conclusion}

This study utilises big data based learning machine media-study on solar power, indicating that this type of method could have uses as a decision support system for corporate decisions, mainly for R\&D investments, policy development and such, for figuring out related public acceptance issues. The results of the study have been in-line with the literature and developments on country level, thus partly validating the used method.

Based on the results, it is clearly visible that solar power production has a neutral and positive public image, which is further emphasised during large national climate congresses such as Paris COP21. The positive image also seems to somewhat correlate with solar power deployment in respective countries. Solar power is seen to benefit from positive media image and public acceptance, clearly visible via social media, influencing the adoption of the new renewable power technologies. Factors favouring solar power deployment include its availability, price decrease and favourable economics and also public acceptance transformed to economic subsidies via political decision making. In this light, the ambitious targets of solar power increase seem to be possible to be met in the future.

The quantitative media-analysis indicates that, on a global level, the subject has attracted much positive and neutral attention in both editorial content and in social media. Especially the social media has a new role in influencing solar power technology acceptance in a positive way. There seems to be a connection between the public acceptance and the global solar power deployment, related politics and regulations. This is clearly evident also in the light of the increased solar power capacity, which has taken place during the recent years. 


\section{References}

Abrahams, A. S., Jiao, J., Fan, W., Wang, G. A., \& Zhang, Z. (2013). What's buzzing in the blizzard of buzz? automotive component isolation in social media postings. Decision Support Systems, $55(4), 871$.

Ashworth, P., Boughen, N., Mayhew, M., Millar, F., 2009. An integrated roadmap of communication activities around carbon capture and storage in Australia and beyond. Energy Procedia 1(1), 4749-4756.

Batel, S., Devine-Wright, P., \& Tangeland, T. (2013). Social acceptance of low carbon energy and associated infrastructures: A critical discussion. Energy Policy, 58, 1-5.

Breukers, S., \& Upham, P. (2015). Organisational aspects of public engagement in european energy infrastructure planning: The case of early-stage CCS projects. Journal of Environmental Planning \& Management, 58(2), 252-269.

Burscher, B., , Vliegenthart, R., de Vreese, C.(2015) Frames Beyond Words: Applying Cluster and Sentiment Analysis to News Coverage of the Nuclear Power Issue. Social Science Computer Review 1-16

Cambria, E., Schuller, B., Xia, Y., Havasi, C., 2013. New avenues in opinion mining and sentiment analysis. IEEE Intelligent Systems 28(2), 15-21.

de Coninck, H., Stephens, J.C., Metz, B., 2009. Global learning on carbon capture and storage: A call for strong international cooperation on CCS demonstration. Energy Policy 37(6), 2161-2165.

Devine-Wright, P. (2007). Reconsidering public attitudes and public acceptance of renewable energy technologies: A critical review. Manchester: School of Environment and Development, University of Manchester, UK.

Devine-Wright, P. (2011). Renewable Energy and the Public From NIMBY to Participation. Earthscan, Routledge, Oxon, UK. ISBN: 978-1-84407-863-9.

Firestone, J., Kempton, W., Lilley, M. B., Samoteskul, K., 2012. Public acceptance of offshore wind power across regions and through time. Journal of Environmental Planning and Management 55(10), 1369-1386.

Godbole, N., Srinivasaiah, M., \& Skiena, S. (2007). Large-scale sentiment analysis for news and blogs. Icwsm, 7(21), 219-222. 
Gupta, N., Fischer, A. R. H., \& Frewer, L. J. (2012). Socio-psychological determinants of public acceptance of technologies: A review. Public Understanding of Science, 21(7), 782-795.

Heras-Saizarbitoria, I., Cilleruelo, E., \& Zamanillo, I. (2011). Public acceptance of renewables and the media: An analysis of the spanish PV solar experience. Renewable and Sustainable Energy Reviews, 15(9), 4685-4696

Hall, N., Ashworth, P., \& Devine-Wright, P. (2013). Societal acceptance of wind farms: Analysis of four common themes across australian case studies. Energy Policy, 58, 200-208.

Huijts, N.M.A., Molin,E.J.E., Steg, L. 2012. Psychological factors influencing sustainable energy technology acceptance: A review-based comprehensive framework. Renewable and Sustainable Energy Reviews 16(1), 525-531.

IEA Technology Roadmap: Solar Photovoltaic Energy - 2014 edition. International Energy Agency, 2014.Retrieved 6/2016.

Jobert, A., Laborgne, P., Mimler, S., 2007. Local acceptance of wind energy: Factors of success identified in French and German case studies. Energy Policy 35(5), 2751-2760.

Khadjeh Nassirtoussi, A., Aghabozorgi, S., Ying Wah, T., \& Ngo, D. C. L. (2014). Text mining for market prediction: A systematic review. Expert Systems with Applications, 41(16), 7653-7670.

Liu, B., \& Zhang, L. (2012). A survey of opinion mining and sentiment analysis. Mining text data (pp. 415-463) Springer.

Matthes, J., \& Kohring, M. (2008). The content analysis of media frames: Toward improving reliability and validity. Journal of Communication, 58, 258-279.

M-Brain. Corporate communications. Received 11/2015.

Menyah, K., \& Wolde-Rufael, Y. (2010). CO 2 emissions, nuclear energy, renewable energy and economic growth in the US. Energy Policy, 38(6), 2911-2915

Nasukawa, T., \& Yi, J. (2003). Sentiment analysis: Capturing favorability using natural language processing. Proceedings of the 2nd International Conference on Knowledge Capture, 70-77.

Neviarouskaya, A., Aono, M., Predinger, H., Ishizuka, M. 2014. Intelligent Interface for textual Attitude Analysis. ACM Transactions 5(3), Article 48.

Ordenes, F. V., Theodoulidis, B., Burton, J., Gruber, T., \& Zaki, M. (2014). Analyzing customer experience feedback using text mining: A linguistics-based approach. Journal of Service Research : 
JSR, 17(3), 278.

Peñalver-Martinez, I., Garcia-Sanchez, F., Valencia-Garcia, R., Rodríguez-García, M. Á., Moreno, V., Fraga, A., \& Sánchez-Cervantes, J. L. (2014). Feature-based opinion mining through ontologies. Expert Systems with Applications, 41(13), 5995-6008. doi:10.1016/j.eswa.2014.03.022

Reis, T., Barroso, A. C., \& Imakuma, K. (2014). Monitoring and analysis of nuclear acceptance by information retrieval and opinion extraction on the internet. Available from Thiago Reis, retrieved on 21 June 2016.

Santos, S. 2015. Oxy-CFB Combustion Technology, It's potential role in $\mathrm{CO}_{2}$-mitigation; $\mathrm{O}_{2} \mathrm{GEN}$ workshop, $18^{\text {th }}$ June, Turku, Finland 2015.

Siegrist, M., \& Visschers, V. H. (2013). Acceptance of nuclear power: The fukushima effect. Energy Policy, 59, 112-119.

Solangi, K., Islam, M., Saidur, R., Rahim, N., \& Fayaz, H. (2011). A review on global solar energy policy. Renewable and Sustainable Energy Reviews, 15(4), 2149-2163.

Sovacool, B., Ratan, P.L., 2012. Conceptualizing the acceptance of wind and solar electricity. Renewable and Sustainable Energy Reviews 16 (7), 5268-5279.

Turney, D., \& Fthenakis, V. (2011). Environmental impacts from the installation and operation of large-scale solar power plants. Renewable and Sustainable Energy Reviews, 15(6), 3261-3270.

Verbruggen, A. (2008). Renewable and nuclear power: A common future? Energy Policy, 36(11), 4036-4047.

Wang, Z. (2010). Prospectives for china's solar thermal power technology development. Energy, $35(11), 4417-4420$

Wolsink, M. 2000. Wind power and the NIMBY-myth: Institutional capacity and the limited significance of public support. Renewable Energy, 21(1), 49-64. 